\title{
El espacio sagrado en la sociedad globalizada: entre el concepto y la identidad
}

\author{
The sacred space in the globalized society: between the concept and identity
}

Giorgio Della Longa (moderador), Steven J. Schloeder, lago Seara, Glauco Gresleri, Jesús Leache y Fernando Tabuenca

Jueves, 12 de noviembre de 2009

https://doi.org/10.17979/aarc.2009.2.1.5038

\section{GIORGIO DELLA LONGA}

Se puede observar que hoy, con este cambio del mundo, con la globalización, que las religiones se han convertido en un fenómeno, un modo de identidad. Y si nos preguntamos cuáles han de ser las respuestas en términos de identidad por lo que respecta a la arquitectura, es porque pienso que todos estamos de acuerdo en que la arquitectura debe promover una identidad. El problema es: ¿qué identidad? Creo que hoy han estado en esta mesa ponentes sosteniendo posturas muy distantes entre sí. Y esto puede alimentar un debate entre varias posiciones.

Aquí no se habla, obviamente, de que se esté buscando una cierta cualidad de la arquitectura, sino una identidad en la arquitectura. Sabemos que hay un problema grave. En Italia se ha abierto últimamente una cierta polémica porque Mons. Gianfranco Ravasi, que es el presidente de la Comisión para la Cultura del Vaticano, interrogado sobre el estado de la arquitectura sacra en Italia, ha dicho que las iglesias son todas iglesias-garaje, iglesias-aparcamiento. Esto sabemos que es un problema. Todos los que estamos aquí sabemos bien que estadísticamente la calidad de la arquitectura religiosa es un problema.

La primera reflexión que se puede hacer es que la arquitectura religiosa se mueve dentro de la arquitectura entendida como un todo. Si existe una crisis total de la arquitectura, yo no acierto a comprender cómo la arquitectura religiosa puede sustraerse de este problema general de la arquitectura. Por tanto, la arquitectura sacra vive dentro del fenómeno general de la arquitectura.

Recordemos algunos puntos que son esenciales en este debate. Uno es el problema de la contemporaneidad. Se ha llamado a ponentes que han hablado de hace cien, de hace cincuenta años. Pero no del problema de hoy. $\mathrm{Y}$ esto es una buena base para la discusión.

Se ha tocado de manera muy diversa el problema de la forma de la iglesia: simplificando, de su planta. Se han hecho recorridos que siguen todavía filones tipológicos o de lecturas del modelo. Por otra parte estarían los nuevos modelos, como por ejemplo la experiencia boloñesa que no ha llevado, de hecho, a una investigación continuada sobre la expresión de la arquitectura sacra. Sabemos que afrontamos problemas que se pueden reasumir incluso desde el punto de vista de la forma, hasta el punto de que la arquitectura religiosa ha asumido casi por completo la dimensión horizontal, descuidando la vertical.

Se ha hablado también del problema de la iglesia en la ciudad. Porque la ciudad cambia, está continuamente cambiando. Aquí se ha dicho, repetidamente, que la arquitectura sacra debía partir del lugar, que ese era uno de los primeros puntos sobre los que apoyar la arqui- 
tectura: la elección del lugar. Y Glauco Gresleri nos ha hecho revivir la elección de lugares en la periferia de Bolonia. Pero debemos ser realistas, y saber que hoy los terrenos elegidos para una iglesia son justo los terrenos más degradados que se pueden encontrar en la periferia de las ciudades. Son los espacios que nadie quiere. Y por tanto, nadie se puede extrañar que se cedan a la Iglesia. Partir de este contexto, que es el problema de la periferia, genera problemas absolutamente diversos para los lugares sagrados.

El último punto que quería enunciar $-\mathrm{y}$ ya le cedo la palabra a mis compañeros - es que el proyecto de la arquitectura religiosa ya no es un hecho colectivo. La iglesia ya no es una construcción colectiva. Pienso que la experiencia de Lercaro fue el último episodio en donde se ha intentado hacer una arquitectura colectiva. Aquí vemos, por una parte, que frente al verdadero y grave problema del arquitecto demiurgo — del arquitecto que proyecta una iglesia a su arbitrio-, hay que reconocer que al arquitecto se le ha dejado completamente solo. $\mathrm{Y}$ esto ha generado el otro gran problema de nuestra época: la soledad del arquitecto.

$\mathrm{He}$ puesto sobre la mesa algunas cuestiones. Podemos hacer una primera ronda de intervenciones sobre el tema de la identidad, empezando tal vez por el arquitecto Seara, dejando cinco o seis minutos para cada intervención.

\section{IAGO SEARA}

Muchas gracias, señor moderador. Rafael Moneo, que fue profesor mío en la Universidad Politécnica de Madrid, decía que el gran dilema para un arquitecto es encontrarse con el papel en blanco en su tablero. ¿Qué hacer en este momento, cómo empezar esta mesa redonda?

Pienso que la identidad es una cuestión que continuamente hay que estar alimentando y construyendo. Por lo tanto, no se trata de concebir la identidad como una cosa estática — que puede ser-, sino más bien de entenderla como algo en permanente construcción. Y dentro del lenguaje de la celebración que estamos discutiendo aquí, yo creo que hay que construir una fe. Hay que construirla a través de una liturgia y un culto. ¿Cómo se concreta esto en un espacio? Con la arquitectura. Confío más en estos planteamientos que en los que son — digamos - más de plantilla, esos de «cómo nos acomodamos». Al igual que ocurre con la amistad, al igual que ocurre con la familia, que hay que estar continuamente creándola y construyéndola, con la identidad ocurre lo mismo. Nos facilita mucho las cosas, aunque nos exige mucho más esfuerzo.

En arquitectura, hay que estar continuamente reflexionando críticamente sobre ella. Se dice que el Movimiento Moderno, la contemporaneidad máxima en arquitectura, está ya superada, está ya en un período postmoderno. Y nunca se estuvo más lejos de la verdad que sosteniendo eso, porque yo creo que la arquitectura siempre está recreándose. Está continuamente haciéndose juicios críticos y de valor, y por lo tanto, está en permanente reflexión. Y esto es lo interesante de toda disciplina: la seriedad y el rigor.

Pero no estamos hablando de disciplina, si no que estamos hablando de emoción espiritual para religarnos en un proyecto común hacia algo que se encuentra más allá, para construir esas metáforas tan maravillosas que hemos visto y construir nuestra comunidad parroquial, diocesana. Estamos viendo cómo en este tiempo vamos asumiendo esa belleza de la liturgia — nos decía en esta mañana el Señor Obispo- y esa belleza que trae la arquitectura. Porque yo creo que la arquitectura religiosa tiene una línea de belleza que tenemos que saber intuir e incrementar con esa otra belleza que es la construcción permanente de una fe.

Sin embargo, la ciudad es un no-lugar. Por eso quiero referirme ahora a la parroquia de Fontiñas, que se implementa en un barrio nuevo, y además, con una tipología arquitectónica totalmente ajena a la comunidad de Galicia. Se planteó crear un núcleo arquitectónico que fuese punto fundacional de dos cuestiones. La primera, la construcción de la fe de esos ciudadanos, que se estaban constituyendo como comunidad a través de la construcción de su templo gracias a un hombre sabio y santo, don Ricardo Viqueira, entregado, preocupado, abierto, sensible y líder. Se fue construyendo ese edificio, implicando a los ciudadanos; se fue construyendo esa fe conjuntamente, en el tiempo y en el espacio - la arquitectura es espacio-, y dándole una belleza: incluso a veces exigiéndome a mí, como arquitecto, más belleza en las propuestas.

Y la segunda, la construcción de un lugar. Honradamente, yo creo que si el barrio de Fontiñas un barrio nuevo cien por cien- era un no-lugar en la periferia, ahora $-\mathrm{y}$ no precisamente gracias a los centros comerciales (la gran plaza del barrio es un centro 


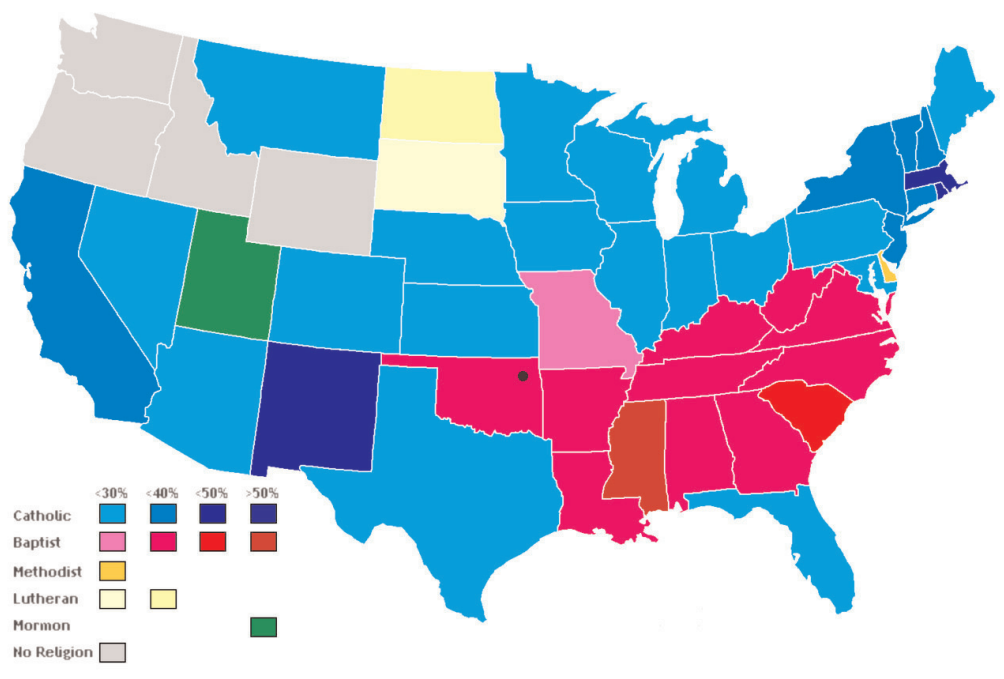

Fig. 1. Religiones mayoritarias en los distintos estados de EEUU. En negro, Tulsa (Oklahoma). comercial: es una cosa absurda pero es así) - ha pasado a ser un lugar de encuentros. La retícula de calles y aceras puede generar encuentros. Pero donde realmente está el auténtico encuentro - y además con la experiencia de religarse a esa alabanza a un Dios Creador por medio de la construcción de un edificio-, es en el edificio de culto, en la iglesia. Y por tanto, este espacio se ha convertido en un punto de referencia - incluso urbanística- de todo el barrio de Fontiñas. Y lo digo porque lo pienso, porque lo siento y porque lo vivo.

\section{STEVEN J. SCHLOEDER}

Bueno, quiero hablar un poco sobre la identidad y lo que significa servir a una parroquia durante un proyecto de construcción.

Durante mi charla de hoy, he evitado deliberadamente mostrar ejemplos de lo que hago, porque quería aportar conceptos generales. Cuando hacemos arquitectura, hacemos una cosa muy personal. Esto ocurre especialmente con arquitectura cristiana. Es una vocación, es algo que Dios nos llama a hacer, es algo a lo que respondemos con nuestros dones, con nuestra historia, con nuestra cultura. Lo que yo hago en EEUU es muy diferente de lo que hace Gresleri en Bolonia. Yo no trabajo en barrios obreros ni en grandes proyectos de viviendas; trabajo en barrios residenciales norteamericanos con recursos, y es algo totalmente diferente. Siempre hay esta relación que necesitamos como arquitectos.

La iglesia siempre debe ser un icono del Reino de Dios, de la Jerusalén celestial, de la Iglesia universal. De muchas formas, esto se nos da a través del lenguaje de la arquitectura sagrada del que hablé esta mañana: en «el Cuerpo», «el Templo» y «la Ciudad». Se nos da a través del derecho canónico, a través de los documentos del Concilio Vaticano II. Tiene razón el papa Benedicto. Y además, hay un lenguaje y una universalidad.

Así que la iglesia es un icono de la Iglesia universal; pero también el templo, el edificio, es un icono de la Iglesia local. Y la Iglesia local se expresa de manera icónica por medio del lenguaje vernáculo local de la arquitectura. Por medio de la socioeconomía de la comunidad, por medio de las limitaciones del lugar, por medio del clima; hay que tratar el clima, hay que tratar la topografía del lugar y el contexto. Por tanto, yo haría un edificio muy diferente en Nueva York, en Florida, en Arizona o en California. Sería diferente debido a las particularidades locales, pero querría que expresase a la Iglesia de manera universal.

¿Qué es lo que me encuentro cuando hablo con mis parroquianos, con mis clientes? ¿Qué es lo que ellos quieren? Ellos no desean un edificio que tenga una apariencia magnífica y que aparezca en la portada de las revistas de arquitectura. Quieren un sitio al que puedan 
ir a rezar y a reunirse con Dios. Si son felices, pueden ir con alegría; si están tristes, pueden ir con su angustia y su dolor y sus problemas, y pueden presentárselos al Señor. El propio edificio es un contenedor de emociones, y como somos seres humanos, nos acercamos al edificio de la iglesia en muchos niveles diferentes. Puede que una persona acabe de conseguir un trabajo nuevo y se sienta muy feliz; otra puede estar en medio de un divorcio o de un matrimonio problemático; otra persona puede que conozca a alguien con un cáncer. Suceden un montón de emociones diferentes dentro del edificio, y el edificio debe contenerlas a todas y ayudar a la gente a entender dónde están en su relación con Dios y con los otros.

Ese es el motivo de que, desde mi experiencia, yo defienda una arquitectura compleja. Una arquitectura de partes que integran el todo. Esto es de lo que hablaba hoy. Estos son edificios complejos que evocan una mezcla compleja de emociones, porque nosotros, como seres humanos, siempre estamos trabajando a diferentes niveles.

Así que, brevemente, quiero mostrarles un proyecto que hice cuando estaba en Tulsa, Oklahoma.

Es una pequeña iglesia de 750 metros cuadrados que se construyó por menos de un millón de euros. Fue un proyecto pequeñísimo. El sacerdote, monseñor Brannigan, se me acercó y me dijo que el obispo acababa de darles permiso para construir una iglesia, y si podía ayudarles. En ese momento, yo estaba trabajando en un gran estadio de béisbol para los Arizona Diamondbacks, y me sentí llamado a abandonarlo y empezar a construir iglesias.

Esta comunidad se encuentra situada en lo que en EEUU se denomina el Bible Belt (cinturón bíblico, ndt), la zona protestante del sur del país (Fig. 1). Hay mucho anticatolicismo allí; hay baptistas, metodistas y evangélicos a los que no les gustan nada los católicos.

En la pequeña ciudad de Collinsville, en 1925 los católicos construyeron una iglesia, un pequeño edificio de ladrillo muy típico con capacidad para unas cien personas. Una noche, el Ku Klux Klan la quemó. Cercaron a los católicos de la ciudad y les dijeron:

— «Podéis ir al norte, a Bartlesville; podéis ir al sur, a Tulsa; o podéis iros al infierno con el Papa».

Así que era una zona donde se había oprimido a los católicos. Pero después de la II Guerra Mundial, volvieron y construyeron una pequeña iglesia, un pequeño edificio de madera que levantaron ellos mismos. No podían comprar materiales de construcción, así que tuvieron que hacer sus propios bloques de hormigón, las armaduras de madera, y construirse ellos mismos el edificio.

Un día monseñor Brannigan se me acercó y me dijo:

- «Quiero que este edificio hable del catolicismo».

Entonces reunimos a la comunidad en el ayuntamiento, y yo les expliqué el lenguaje de la arquitectura.

Querían algo que realmente fuese una declaración de fe.

Esta es la entrada del edificio. Lo primero que querían ver era el baptisterio. Eso era lo primero que querían ver, porque entrar en la iglesia es una conversión. Querían la entrada principal y un lugar para reunirse. Ellos habían celebrado el culto en un lugar más pequeño que esta sala en la que estamos, y querían conservar una sensación de intimidad. Pero tenían que acoger a unas 400 personas: ¿cómo lograr eso?

Aunque es un edificio pequeño, yo quería diseñarlo de manera teológica (Fig. 2-4). Bajas tres escalones y allí está el baptisterio. Atraviesas la puerta principal y dentro se encuentran los confesionarios, porque el sacramento de la reconciliación es una verdadera entrada en la liturgia. Hay un pequeño nártex, una sala de reuniones muy luminosa, servicios... Pero tiene forma octogonal. Es un edificio compacto porque yo quería conseguir una sensación de intimidad. Hay un deambulatorio que te envuelve con capillas para los santos. Antes no tenían capillas porque no había sitio; había una Santa Teresa - éste es, de hecho, el santuario de la santa titular de la diócesis - y el altar está en el punto de unión del presbiterio y la nave, donde se reúnen el Cielo y la Tierra: ahí es donde está el altar.

Hay dos capillas laterales; al este la capilla de María, Nuestra Señora, donde hemos puesto una hermosa vidriera de color azul. Por la mañana, cuando la luz es pálida, da una calidad de luz muy hermosa. La capilla del oeste es para orar por los muertos. Tiene una hermosa crucifixión en color rojo. La luz entra allí por las tardes, cuando el sol calienta. Como ven, la calidad de la luz está cambiando constantemente a lo largo del día. Finalmente, la capilla del sagrario está en la parte de atrás; una vez más, un edificio sencillo.

Su forma es románica — de estilo románico—, pero eso no es importante. Lo elegimos porque la comunidad 

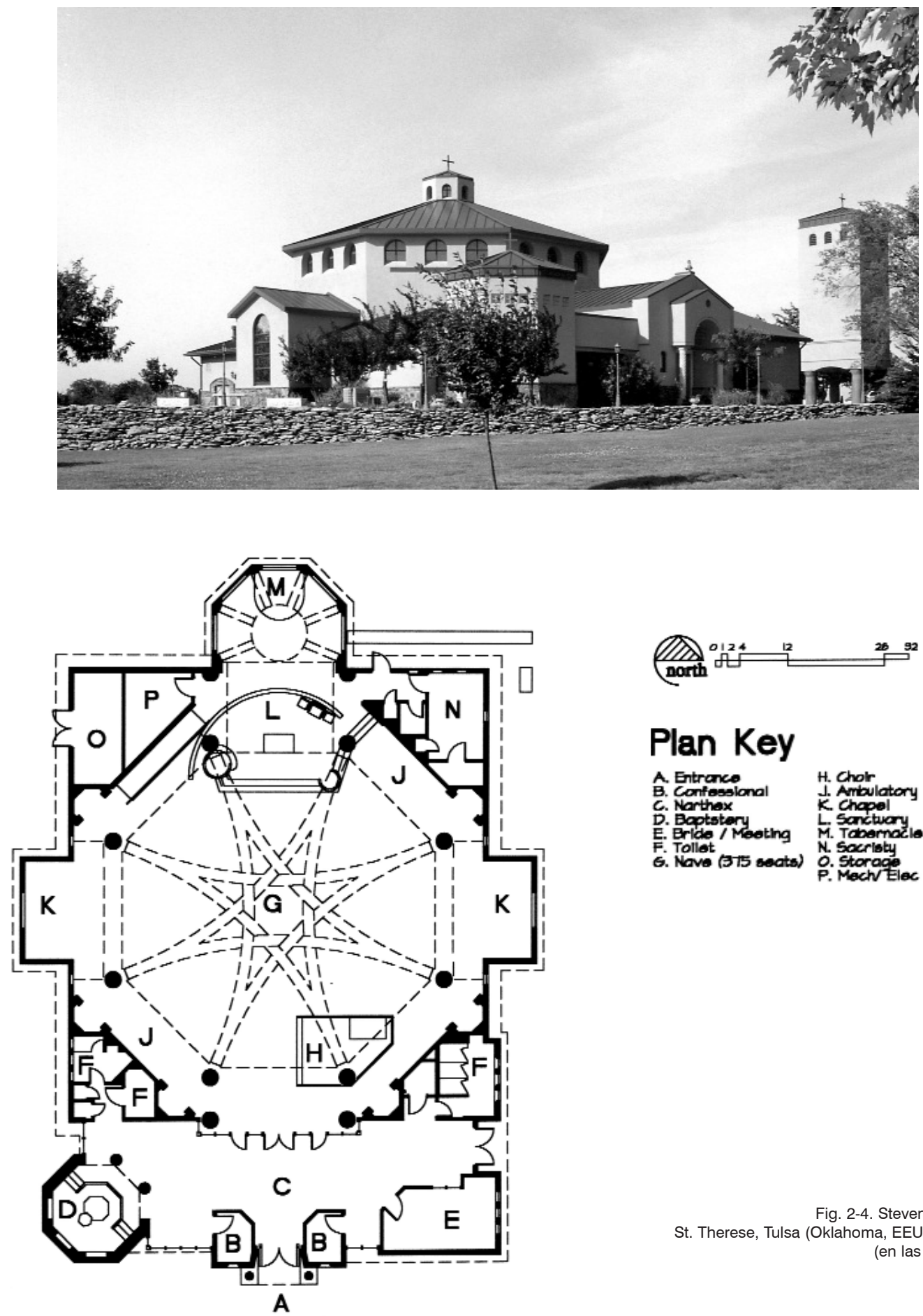

\section{Plan Key}

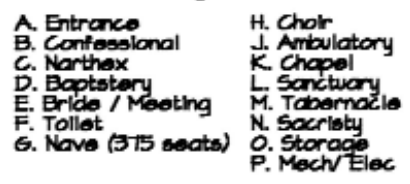

Fig. 2-4. Steven J. Schloeder St. Therese, Tulsa (Oklahoma, EEUU), 1996/2000 (en las dos páginas). 


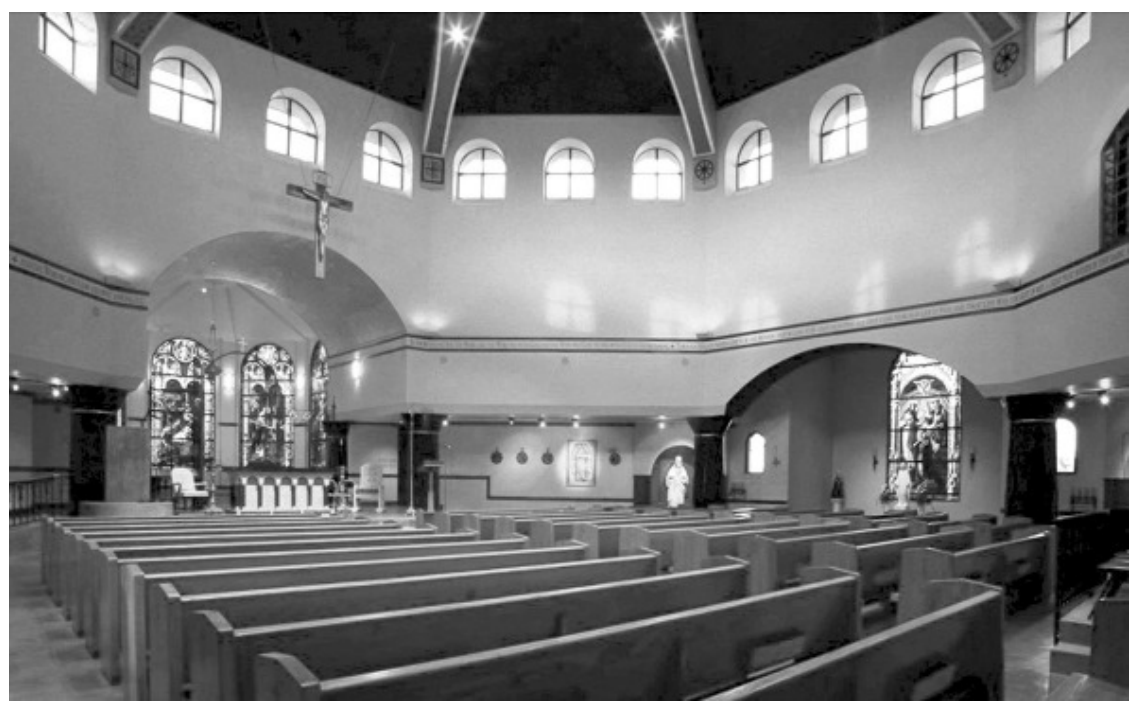

sintonizaba con ello, pero no tiene importancia. Funcionaba con la topografía básica de Oklahoma, funcionaba con la calidad del sol: una vez más, es la relación entre forma y función la que creó toda la masa general.

Hay doce columnas que representan a los doce apóstoles, y veinticuatro ventanas que representan a los veinticuatro ancianos sentados en el trono celestial. No lo veis bien, pero este techo tiene un entrelazado que forma la rosa mística, una pequeña flor, como si fuese una flor del jardín celestial.

Todo el edificio es muy pequeño. Y es una respuesta particular para una comunidad particular.

Volví allí hace unos años. Y una señora me llevó a un aparte y me dijo:

— «Steve, este edificio me habla en silencio sobre nuestra fe».

Y esto es lo que debería hacer un edificio: no debería usar las palabras para describir nuestra fe.

Este edificio es la iglesia donde me casé. Mi esposa quería casarse en un edificio bonito. Le dije que conocía uno y nos casamos allí. Sólo quería mostrarlo como ejemplo de cómo algo puede tener sentido si somos capaces de avanzar en nuestra fe católica.

\section{GLAUCO GLESLERI}

Creo poderme conectar de forma especial al segun- do ponente, y sobre todo, a un principio que él ha citado que es el principio de la complicidad. Porque el edificio que podemos identificar con el término iglesia es, sobre todo, el que parte de su concepción parroquial. Tenemos de hecho muchos tipos de iglesias, pero la más difícil de tratar es la iglesia parroquial, porque en el interior de sus propias funciones $-\mathrm{y}$ en el ámbito de las significaciones que expresa y de los contenidos con los cuales tiene que comunicar- es extremadamente compleja. Y examinando arquitectónicamente la complejidad de la instalación, nacen las infinitas posibilidades diferenciadas de la planta. ¿Por qué se ha perdido la posibilidad o hasta la idea de poder constituir una nueva tipología de iglesia parroquial según la nueva liturgia? Porque en el momento en que nosotros analizamos e intentamos poner en valor todas las funciones que se manifiestan dentro de la iglesia parroquial, nos encontramos con que tenemos que maniobrar entre una complejidad de dificultad extrema.

La diferenciación puede ejemplificarse significativamente citando algunos casos. En el momento en que nosotros empezamos a distribuir una masa, digamos, de presentes — la familia — de algún modo alrededor del altar, podemos ponerla en batería de frente, imaginando que la comunicación pueda acontecer de forma directa y frontal; podemos extenderla en los lados; podemos incluso ponerla en la parte de atrás, mirando hacia el 
altar. A medida que movemos la asamblea de esta forma, no sabemos dónde situar el ambón, porque en una situación lineal, de dos frentes - el altar, con o sin presbiterio, y la asamblea-, la corrección del ambón pide acercarse a la asamblea todo lo que se pueda, es decir avanzar lo que se pueda hasta el punto que esté muy cerca de la asamblea misma. Pero a medida que pasa eso, a ojo, en la solución con la asamblea colocada en los laterales, ¿el ambón dónde queda? El ambón se tiene que desplazar hacia atrás, hasta que al final lo llevo tan lejos para que pueda tener una relación proscénica con todos; aunque justamente, en virtud de esa «proscenicidad», a medida que aumenta la distancia se pierde su valor comunicativo. Éste ya es un momento muy difícil, y es cuando cada vez me encuentro sin saber qué hacer.

En la última iglesia que he proyectado, no sabiendo dónde poner ese bendito ambón, me he acordado de una iglesia que había hecho cuando tenía veintiséis años, en Imola. Es una iglesia cuadrada, con la asamblea que se distribuye en todos los lados. Una iglesia que, sin embargo, tiene una vivacidad, digamos, de actividad increíble. Por ejemplo, el domingo los niños en vez de ir por ahí, van todos a la iglesia, se quedan en el interior de la misma, con bancos de madera muy sencillos que cierran toda la asamblea. No me acordaba de esta solución y fui a verla otra vez. Había puesto el ambón muy lejos, al fondo, detrás de la iglesia, para que pudiese, digamos, comunicarse de verdad con toda la asamblea.

Pero éste es uno de los problemas. La misma situación del ambón, como vosotros podéis observar, en las iglesias nuevas es completamente distinta. En las iglesias de antes se encuentra a veces en la esquina de la izquierda, otras veces delante, otras veces detrás. ¿Dónde ponemos ese ambón? Porque a medida que lo empujo hacia la asamblea...

Ahora, en la catedral de Reggio Emilia, durante una reestructuración, no sólo se ha llevado más adelante, sino que se ha colocado en el medio de la asamblea, cosa que ha sido realizada también en unas iglesias alemanas. Pero si se sitúa delante, en la asamblea, no puede orientarse ni hacia un lado ni hacia el otro, tiene que estar en un lado. Estando en un lado comunica poco. Entonces en Reggio Emilia se ha utilizado el viejo púlpito, y así el ambón se ha transformado en púlpito, el sacerdote habla desde lo alto y evidentemente comunica con todos. El hecho de hablar desde lo alto tiene otro significado, de homilía contada de una forma distinta respecto a como la contaba Lercaro, y entonces ya no sabemos dónde poner ese bendito ambón.

Luego hay que añadir otras cosas. Tradicionalmente la fuente bautismal se ha puesto en la entrada de la iglesia. La entrada representa el sitio de inserción en la comunidad y está bien que así sea. Pero en el momento en el que, por motivos tanto prácticos como de celebración, en el ámbito de la liturgia general que manifiesta la iglesia en muchas soluciones, la fuente bautismal se lleva hacia la zona del altar — para que en el momento de la celebración del bautismo la asamblea misma, eventualmente ya constituida, pueda participar en este sacramento-, entonces hay que intentar hacer el presbiterio, luego el altar y luego la fuente bautismal para ver la dificultad en la que nos encontramos.

De la misma manera el lugar del perdón. Claro, los confesionarios los podemos situar cerca de la puerta, en unos rincones escondidos para aislar a quién se libera del pecado. Pero ¿es justo que esté escondido, o el lugar del perdón lo tengo que poner en medio de la iglesia? De esta manera quien entra, es cierto, entra como pecador hasta la muerte, pero sale casi santificado. Por lo tanto, tiene que salir radiante. Y la asamblea aclama porque esta persona que era un pecador, sale santo. ¿Por qué entonces tiene que esconderse en un rincón? Quiero decir, lo mismo pasa con los lugares devocionales o con la reserva de la eucaristía.

Nosotros tenemos que pensar que la reserva eucarística nació como «nevera». Cristo es puesto ahí para que se sepa que cuando se necesita - cuando hay algún enfermo, alguien en trance de muerte, por ejemploesté presente, se pueda recuperar. Pero no se esconde en un elemento cerrado y llevado lejos, sino que usamos una solución distinta, porque como presencia viva, yo no puedo ignorar Qué es lo que se encuentra en esa posición, no puedo no dirigirme ahí un momento y hacer un ademán de reverencia, de profunda adoración. Entonces, ¿dónde lo pongo? Porque me revoluciona todo el espacio de la iglesia...

Y así podéis ver la cuestión de la complejidad. En la organización litúrgica de la iglesia parroquial existe un nudo fundamental de dificultad de la organización del espacio, teniendo en cuenta que luego, al final, este espacio tiene que ser un lugar que, en su complejidad, tiene que estar claramente concebido en su unidad general. Por eso, el hecho más importante es conjugar 
complejidad con unidad, y hacerlo de forma que todo resulte expresivo y feliz. Ésta es la dificultad de ese pobre arquitecto que tiene que ofrecer una solución para todo.

Y lo de entender... porque es algo escolar. Hay quien dice que no podemos hacer nada solos, sin la presencia de expertos de todo tipo: expertos litúrgicos, expertos en acústica, expertos en luminotecnia, expertos en sonido, expertos en movimiento, expertos en coros... En cambio, el pobre arquitecto tiene que poseer todas estas experiencias para poder enfrentarse con la hoja en blanco. Las competencias está claro que son importantes, pero son importantes en sus sedes, no en la sede arquitectónica. La sede arquitectónica es el momento poético en el cual una sola persona hace poesía. Es como decir que para hacer poesía se necesita el experto en gramática, el experto en sintaxis, el experto en comas, el experto en el énfasis, el que dice si «famiglia» se escribe con «gl» o sólo con «l». Todos estos expertos los dejas en la puerta. Y entonces Leopardi empieza: «Sempre caro mi fu quest'ermo colle» etc. Son las palabras correctas las que hacen poesía, y él empieza con «Sempre» (siempre), para eliminar todo tipo de duda: no es ni antes ni después, sino que «Sempre», «sempre caro». Después tenemos la palabra «caro» (querido), para que todo el mundo pueda entender. En dos palabras ya lo ha dicho todo: «mi fu, quest'ermo colle» (me fue, esta colina bonita): «mi fu», dice, desde que era niño, «ermo», bonito, porque quiere explicar cómo es. En la arquitectura ocurre lo mismo. En la arquitectura, el arquitecto — pobre de él- se encuentra solo, y después de haber asimilado todas las ciencias, consultando a todos los expertos - con anterioridad, porque cuando él realiza la arquitectura no puede tener uno al lado que le diga «coge el lápiz de esta forma y luego traza esta línea aquí»— la arquitectura es un momento poético de síntesis, en el cual toda la complejidad acaba en una unidad única, reconocible y resolutiva: es un momento mágico. A veces se consigue, otras veces no: y nos santiguamos para que el momento mágico acontezca.

\section{JESÚS LEACHE}

Es realmente complicado decir algo inteligente y con sustancia después de estas intervenciones, especialmente de la más próxima. Porque Glauco ha glosado perfectamente todas nuestras inquietudes, todo el cal- vario que nosotros hemos pasado cuando nos hemos tenido que enfrentar al problema que mañana les contaremos.

Giorgio, al principio, se ha referido a algunos temas generales importantísimos. Debo decir que nosotros hemos venido aquí no como teóricos de la arquitectura, ni como teóricos de la arquitectura religiosa, sino como prácticos, como «prácticos del puerto» ¿no? Como prácticos que nos acabamos de enfrentar al problema concreto de la construcción de una iglesia. Un problema de síntesis, como Glauco acaba de afirmar. Y un problema gozoso. Por un lado, porque el proyecto de una iglesia quizá sea el proyecto más maravilloso con el que alguien se puede enfrentar. Y posiblemente también el más complejo, dentro de su extremada sencillez. En fin, plantea un cúmulo de cuestiones a las cuales nosotros hemos amanecido hace unos años. Sobre cada uno de los temas que se han tratado hay una cantidad de preguntas infinitas y casi insondables. Lo comentamos muchas veces en el despacho: la historia de la arquitectura es la historia de la arquitectura religiosa, y todos los problemas de la arquitectura están en la arquitectura religiosa. Con lo cual, estos debates podrían ser infinitos.

Giorgio decía: ¿Qué pude aportar la arquitectura? Y yo he tomado aquí algunas notas hilándolo con lo que planteaba Glauco. Esa frase que él decía — y que me ha parecido fantástica-, ese grito de: ¡Sed urbanistas antes que arquitectos!, y que yo suscribo plenamente, quizá debería grabarse, esculpirse en piedra. Hemos dejado de ser urbanistas, nos hemos olvidado de la ciudad, y las iglesias, finalmente, siempre han sido el remate de las ciudades, su epicentro, su elemento organizador, articulador, el punto de aplicación de la energía, la silueta de los pueblos, de las ciudades. Y todo esto se nos ha venido abajo.

Con lo cual, quienes hoy nos enfrentamos -en nuestro caso ha sido sólo en una ocasión, a raíz de un modesto concurso - a este problema, por un lado tenemos en nuestro imaginario la excelencia y la maravilla de lo que supone la arquitectura religiosa; pero por otro lado, cuando descendemos al plano de lo real, nos encontramos unas herramientas de trabajo que no son esa ciudad maravillosa que vemos en Camilo Sitte, en su libro de arquitectura civil, con ejemplos de la ciudad medieval europea, perfectamente imbricada, con esos espacios que la hacen apasionante. Sino que nos enfren- 
tamos con una ciudad absolutamente degradada, especuladora, arrasada, sin carácter y sin iglesias. Y en donde, de repente, hay que poner una iglesia.

Nos encontramos también con unos sistemas constructivos y con unas paletas de materiales infinitas, en una construcción, a su vez, absolutamente empobrecida, precisamente por todas esas posibilidades que ofrecen los sistemas constructivos hoy en día. No podemos dejar de pensar en que el éxito, la excelencia y la maravilla de la tradición de la arquitectura religiosa heredada desde las basílicas romanas, está precisamente en esta unidad constructiva coherente, monumental, que crea un sistema de espacio y luz perfectamente hilados. $\mathrm{Y}$ esto, hace cuatro días, se nos ha venido abajo.

Nos encontramos con un panorama de vocaciones inexistentes, de una fe desaparecida. Nosotros nos consideramos jóvenes a medias, y en la corta trayectoria que llevamos como arquitectos, pues realmente, cuando uno termina un edificio - sobre todo si tiene un carácter público - se produce esa desazón entre que uno termina la obra y comienza su uso. Y uno desea que la obra sea usada y sea vivida, y poder comprobar esas experiencias. La obra está hecha para ser vivida y para ser usada. Me gustaría ver nuestra iglesia llena y abarrotada de gente y de fe, y realmente, ahora los fieles se desperdigan por los bancos.

Nos encontramos con un arte sacro volatilizado. Tenemos que ir a las bibliotecas a coger libros antiguos, quitarles el polvo e ir hacia atrás hasta poder, rebuscando, encontrar algo a dónde poder agarrarnos. Hay un desierto absoluto, y nadie sabe, nadie contesta. $Y$ estamos en una situación de orfandad que si alguno de ustedes la ha vivido, sabrá que es impresionante poder comprobarla.

Nos encontramos - dentro de nuestra ignorancia y no especialización en este tema tan importante- con que a pesar de que existen unas directrices litúrgicas derivadas de los concilios y de las cartas de los Papas, no parece que acabe de haber un consenso total. Realmente hemos asistido a reuniones sobre las cuestiones litúrgicas donde no había consenso, donde subyacía la existencia de un problema.

Nos encontramos con la particularización litúrgica de las comunidades cristianas, donde cada uno tira de una esquina de la manta. Y nos encontramos, vuelvo al principio, con esa tradición de la construcción interrumpida bruscamente. Y eso es dramático.
Y entonces nosotros nos vemos en la obligación o más bien no tenemos otro remedio- que construir con otras herramientas, como son la intuición o la energía. Quizá la energía puede ser el hilo conductor de la tradición de la construcción. La energía es fundamental en la arquitectura, porque la arquitectura sin energía no es arquitectura. Aquí se ha hablado de poesía; sí, pero un espacio sacro tiene que tener energía. Necesitamos tener fe: cada uno a su modo, pero fe. Y necesitamos utilizar el rigor. Sabemos que hay que ponerle entusiasmo, hay que aplicarle vocación y hay que aplicarle muchísimo esfuerzo. Esas son las herramientas con las que nosotros tenemos que trabajar.

Realmente, cuando en su día nos enfrentamos al problema de esta iglesia que mañana presentaremos, nos dimos cuenta de que quitarse el lastre de una tradición de siglos de la noche a la mañana era imposible. Sencillamente imposible. No podíamos coger el lápiz y decir: «Voy a resolver el problema; no os preocupéis, muchachos, que yo lo resuelvo.» Desde luego, a mí me da una tranquilidad tremenda oír a Glauco reconocer que esto sigue siendo un problema. Eso es reconfortante. $\mathrm{Y}$ es importante que todos sepamos que hay un problema: reconocer ese problema, vivir con ese problema, con esa falta de definición.

Durante el viaje hacia aquí, veníamos revisando algo de bibliografía que traíamos un poco al hilo. Íbamos viendo todos estos problemas que Glauco ha planteado: qué se siente hoy en día, qué hago con la asamblea: si la llevo para allí, entonces... si le doy la vuelta, le doy la espalda a quien celebra... En fin, formas de asambleas: el camino, el hemiciclo, etc. Cuando nos planteamos hacer este proyecto visitamos algunas iglesias en Madrid. En fin, todas esas iglesias del postconcilio: de Luis Moya, de Fernández del Amo, de Corrales y Molezún. Lo dice Alberti: cuando te enfrentes a un problema nuevo de arquitectura, vete a ver qué han hecho los demás y qué experiencia han tenido, desde el punto de vista funcional, constructivo, etc. Y después de haber revisado estos ejemplos de arquitectos ilustrísimos y fantásticos, algunos de ellos profesores nuestros, pues nos dimos cuenta de que ¡teníamos un problema!

Con lo cual, sentimos el peso de lo que supone en día de abordar el proyecto de una iglesia, dejando aparte el hecho de que en sí mismo, el tema - y esto nos lo decía el párroco- era tan importante como que ¡es la 
casa de Dios! Y cuando te lo cuentan así — Bethel, creo que es hebreo-, te tiemblan un poco las piernas. Porque hemos hecho casas para algunos clientes, vale, pero ¡la casa de Dios! Y además, ¡te vas a enterar ahora de los problemas que tiene la casa de Dios! Realmente es muy complicado, muy complicado.

Yo creo que nosotros estábamos en una situación parecida al que va a cruzar un pequeño riachuelo y está descansando firmemente sobre una roca seca, que no se mueve, y que si uno la pisa no se cae porque no desliza. Pero que tiene saltar a otra piedra que está más allá de la distancia de un paso, que está ligeramente moja$\mathrm{da}$, tiene un poquito de musgo y tampoco está claro si el apoyo de esa piedra es demasiado firme... Yo creo que en esta ocasión nosotros nos hemos quedado como en el aire, congelados. Quiero pensar que no nos hemos quedado en la piedra en donde estábamos, pero no se ha producido ese salto. Y creo que tampoco - igual estoy diciendo una barbaridad - lo ha llegado a hacer nadie.

Con esto termino. Creo que hay que pensar en la tradición histórica de la arquitectura religiosa, en la decantación de sus tipos y en su funcionamiento. El tiempo que llevamos desde el Concilio Vaticano II, experimentando con modelos que van cambiando casi permanentemente, produce una desazón absoluta.

\section{GIORGIO DELLA LONGA}

Yo propongo una segunda y rápida ronda de intervenciones, a propósito de una pregunta que es casi una provocación.

Todos estamos en Occidente, pero Occidente es muy diverso. Por eso se entiende que la petición que tras la Segunda Guerra Mundial hace Lercaro a los jóvenes arquitectos de Bolonia, sea una petición profundamente distinta de la que le hace a Steven Schloeder la comunidad que le encarga una iglesia, y que conduce a resultados profundamente diversos.

Parto de una imagen que hemos visto esta mañana en la presentación de Schloeder, aquélla en la que se veía uno de los eslóganes de la Modernidad: «La forma sigue a la función». Yo no estoy muy de acuerdo con lo que se ha dicho, porque se ha propuesto en forma negativa y justamente, entiendo, porque éste ha sido uno de los grandes equívocos. Pero creo que el problema es muy otro, en este asunto de que la forma siga a la función. Es cierto que en los años treinta, en los años heroicos de la Modernidad, este era uno de los grandes mitos. Al menos, había una idea muy clara de que debía ser seguido. Yo me acuerdo que en un número de Casabella de 1930 donde aparecía publicada una iglesia de Dominikus Böhm — la única iglesia de Dominikus Böhm cúbica, blanca, racionalista-, el comentario del crítico era que el fiel que entraba en una iglesia ya no podía reconocerse en el barroco, en el incienso o en las velas, pero sí que podía reconocerse en aquella iglesia blanca, porque ese fiel practicaba la gimnasia, seguía unas reglas higiénicas y por eso se debía encontrar bien en una iglesia blanca. Era un momento verdaderamente problemático en la aproximación hacia una nueva identidad de la iglesia.

Pero en mi opinión, la dificultad con la que nos encontramos es que, al menos en las obras de un cierto interés, las respuestas a este problema son absolutamente arbitrarias. Por ejemplo, si nos fijamos en lo que se refiere al símbolo, podemos decir que los símbolos de la tradición no se utilizan, y que cada arquitecto se inventa nuevos símbolos. Esto ocurre, por ejemplo, con el simbolismo de la estructura, con la gratuidad de las grandes estructuras, que han sustituido a los símbolos de la tradición cristiana.

Aquí tenemos un nuevo problema, y formulo una cuestión que creo que es radical. Yo he conocido arquitectos que defienden que la forma de una iglesia es una forma ya definida de una vez para siempre - estoy provocando, estoy simplificando al máximo-, y que, por lo tanto, la evolución de la arquitectura es una continua transformación y metamorfosis de esa forma basilar que es la forma de la iglesia que proviene del vocabulario de la historia. Por el contrario, he conocido a otros arquitectos que piensan que la renovación de la liturgia aporta nuevas reglas que permiten alejarse de los esquemas establecidos para crear una nueva forma de iglesia. Hay un documento en Italia - exactamente el documento de la Conferencia Episcopal Italiana sobre la proyectación de las nuevas iglesias - que en un momento de su presentación dice: «...la forma de la asamblea que plasma la forma de la iglesia». Yo personalmente pienso que esto es - ¿cómo lo diría? - una aspiración que hay que buscar, pero que raramente se realiza. Creo que es casi una utopía. Porque la arquitectura tiene su propia autorreferencialidad y sus reglas, que son independientes de todo esto.

Pero pregunto. ¿Es posible que se recomience desde el Concilio Vaticano II, con su renovación litúrgica, y 
que sea posible que esta renovación dé lugar a nuevas iglesias dentro de las cuales se encuentre la identidad?

\section{IAGO SEARA}

Al principio se preguntó: ¿Cuál es el problema de la construcción de una fe comunitaria en un espacio periférico que por desgracia es un no-lugar? Esta es la realidad de nuestro urbanismo. Yo creo que con un solo edificio no se hace urbanismo, y que cuando se construye una iglesia parroquial, desde la diócesis no se está haciendo un planteamiento urbanístico. Esto hay que centrarlo. Lo demás son explicaciones que nos desvían del problema.

La realidad es que en el urbanismo, cuando es de participación, se distribuyen unas compensaciones, contraprestaciones y cesiones para equipamientos. Normalmente, para equipamientos se cede el solar de menos importancia. Y de ese patrimonio de solares en suelo urbanístico que recibe un ayuntamiento - estoy hablando del caso latino, mediterráneo-, cuando éste a su vez lo cede para una iglesia cede el peor de esos solares, el más degenerado. $Y$ en ese no-lugar se construye una iglesia.

¿Cómo se hace esto, además, en una ciudad que normalmente no tiene equipamientos —ágoras - para el encuentro ciudadano? Yo puse el ejemplo de Fontiñas porque me parece ejemplar; porque supone un ejercicio de responsabilidad a través del ejercicio de la construcción del templo, que además es el símbolo y la resignificación de una fe que se está construyendo. Y esto a mí me parece importante.

¿Con qué fieles se está construyendo esa parroquia en la periferia? ¿Y qué bagaje, qué tesoro heredado, como valor de acto creador y cultural, tenemos en esos fieles? ¿De dónde vienen? ¿Es la primera generación que viene del rural? ¿Cómo vivían la fe en el rural? Todo esto hay que tenerlo en cuenta. Tal vez había un atrio, un camposanto alrededor de la iglesia, y se reunían allí. Esa gente ahora está aquí. Hagamos entonces lo mismo, pero con los modelos y tipologías que tenemos en nuestro repertorio. Porque yo no creo que se pueda interpretar esto como una renuncia a una tradición. Es erróneo, igual en la arquitectura, renunciar a una tradición, entendiendo la tradición como algo continuo que siempre estamos renovando. $\mathrm{Y}$ en ese aspecto, he querido hacer una matización a la primera contestación que he hecho.
Con respecto a la segunda pregunta, creo que todas las cuestiones, desde un punto de vista de la reflexión profunda y seria, están vinculadas siempre al tiempo y al espacio. Nuestra tradición católica está vinculada a unas relaciones temporales y espaciales. No se puede desvincular la liturgia como idea que genera un proyecto, de los programas o propuestas teórico formales de la razón de ser del templo. Es una tradición que se va creando continuamente. No se puede separar tiempo y espacio. El tiempo creo que lo marcan la liturgia y el culto: la continua recreación de la fe en comunidad para religarse a una cuestión superior que es la alabanza a un Dios Creador, que se celebra día a día. Y eso me parece que ocurre en nuestra tradición. Como dice la Constitución sobre la Sagrada Liturgia, es un tesoro heredado - un patrimonio heredado, diríamos hoyen la cultura. Y por lo tanto, no entiendo las preguntas — perdonen que les diga-, porque se salen un poco de toda esa tradición.

En Fontiñas hay un atrio. Porque en nuestra cultura urbana, no popular, se entra en el territorio sagrado por una puerta. Ese recinto es el lugar en el no-lugar. Y el encuentro se produce ahí, y ese es el punto de referencia para un buen urbanismo, para un buen uso de la ciudad. Creo que es muy sencillo: entras en el atrio y te encuentras en un camposanto o no - porque en Galicia, hasta hace poco permitían enterrar a los difuntos alrededor de la iglesia-, pero lo vives. Y la gente sale de misa y se va al atrio aquél, y está allí, en ese césped elevado, y entra si quiere en la nave, en el templo. Y en el templo se encuentra en un sitio recogido por medio de una luz.

Bueno, yo creo que estas son las cosas que hay que hacer: no tanto mirar a la forma, no tanto discutir si primero es razón o función, si no realizar un estudio antropológico de nuestros fieles, que también son ciudadanos. A veces están ahí las claves, no en la tipología. Yo no creo en eso tampoco. Lo dije por la mañana: creo que la idea genera una forma. Si miramos tanto esas cuestiones nos perdemos la verdad. Y yo creo que es ahí donde debemos situarnos, perdonen los ilustres compañeros de la mesa. Gracias.

\section{STEVEN SCHLOEDER}

Para responder a tu pregunta tan diversa, hay una serie de cosas que aparecen en capas.

Primero, deja que responda a si la forma sigue a la 
función o si es la función la que sigue a la forma. ¿Sigue la forma - como de la mano- a su función o viceversa? Creo que es una falsa disyuntiva. Pienso que Tomás de Aquino puede enseñarnos que la forma y la función son dos aspectos del ser. Estamos tratando de crear un lugar que es la quintaesencia de un ser superesencial, Jesucristo; de la adoración de la Santísima Trinidad; de los ángeles y de los santos; la forma, la función, la ubicación, el significado: todo aparece junto. Resulta falsa la noción de intentar separar todas estas cosas.

La cuestión del simbolismo. Los símbolos son intrínsecos a la condición humana, y hay un lenguaje de símbolos que se desarrolló a lo largo de la historia. Y aquéllos símbolos que perduraron, aquéllos que permanecen y que continúan conmoviéndonos y afectándonos, que orientan y dan significado a nuestras vidas, son los más primitivos. ¿Por qué es la eucaristía pan y vino? Porque nos alimenta y nos da alegría. ¿Por qué se usa el agua en el bautismo? Porque nos ahogamos en ella, la usamos para beber, para regar las plantas y para lavarnos. Estos son símbolos sencillos que usa Dios para comunicarnos la gracia. No podemos inventar una nueva simbología.

Este es un auténtico problema para el arquitecto moderno, que piensa que es un sacerdote ungido para dar un nuevo significado a algo que es antiguo, que es trascendente y que está más allá que todos nosotros. Y pienso que le hace un flaco servicio a la comunidad, a la Iglesia universal y a Dios, el pensar que un arquitecto tiene una intuición sobre lo que es la liturgia que puede sobreponerse a dos mil años de tradición. Es de un orgullo y de un ego desmedidos el pensar que podemos hacer eso. Más bien, hay que someterse a la tradición, a la Revelación. O bien creemos en la Encarnación, creemos sencillamente en la verdad revelada, creemos en las Escrituras, en la Tradición que se nos legó, o no creemos y las inventamos. La religión exige tradición; no puede ser inventada de la noche a la mañana.

Por eso me molesta la pregunta sobre si ha cambiado la forma de la liturgia. Me irrita la idea de que hay una nueva liturgia. No hay una nueva liturgia, no se hizo nada nuevo; el Movimiento Litúrgico no inventó nada nuevo. Os animo a volver a la obra de Pío X: Tra le Sollecitudine. En este documento de 1903, el Santo Padre escribe sobre la dignidad y el cuidado del templo, y la importancia del mismo, ya que el católico medio encuentra en la iglesia la principal ubicación de la gracia. La dignidad del templo: Pío X habla sobre ella en términos específicamente arquitectónicos. Y el cuidado de la liturgia: el edificio de la iglesia es un vehículo de la gracia, es un sacramento. No podemos empezar a jugar con los símbolos, especialmente con los símbolos sacramentales.

Para mí, la pregunta realmente es ésta: ¿cómo creamos un edificio que ayude al fiel cristiano a entender su lugar correcto dentro del Reino de Dios, su verdadero lugar en la comunidad? Y con esa frase comienza Pío X aquel documento escrito en 1903, en el que habla de la participación activa, lo que significa — según yo entiendo- que entramos en la liturgia plenamente como seres humanos compuestos de cuerpo y alma, con nuestra memoria y nuestra imaginación, como seres humanos plenos.

La gran pregunta del Movimiento Litúrgico a lo largo del siglo XX fue: ¿cómo fomentamos la participación activa? Y realmente, la respuesta se encuentra en la Sacrosanctum Concilium y en los escritos de Juan Pablo II: ofrecemos nuestras vidas en sacrificio. Pienso que eso es lo que significa para nosotros, como católicos, que los miembros del sacerdocio bautismal se unen a los miembros del sacerdocio ministerial para ofrecer sus vidas en sacrificio en conjunción con el sacrificio de Cristo. Eso es la liturgia, esa es la obra de la gente. $\mathrm{Y}$ eso es lo que el edificio merece.

Liturgia. La liturgia no ha cambiado. No es necesario un nuevo paradigma. Podemos hablar de la distancia entre el altar y el pueblo, de cuál es el mejor modo de mantener la comunicación con el pueblo, que es de hecho - un problema de escala. En una sala pequeña como esta, yo veo a todos y todos me ven a mí. Históricamente, existen edificios mayores: tienes el gótico, el barroco, la propia arquitectura sirve de dispositivo mediador. El uso de columnas, de pilastras y de cornisas ayuda a crear una escala humana. ¿Cuántos de nosotros hemos estado en San Pedro del Vaticano? Puedes estar a cien metros de distancia y ese grandioso baldaquino genera una zona sacra que te ayuda a dirigir la atención hacia allí. Por tanto, puedes estar muy distante y seguir sintiéndote involucrado.

El problema de la arquitectura moderna es la eliminación de esos dispositivos mediadores. Hay una sabiduría cierta en la antigua manera de hacer las cosas que 
nosotros, como arquitectos modernos, debemos recuperar. Por eso, si construyo una iglesia para dos mil personas, tengo que conseguir que alguien que esté a cien metros de distancia pueda seguir sintiéndose conectado. Esa es la respuesta a tu pregunta.

\section{GLAUCO GRESLERI}

Hay que decir que todo lo que ha dicho Steven Schloeder es muy interesante y muy verdadero. Estoy de acuerdo con el hecho de que en la iglesia están los fieles, y para que los fieles puedan participar activamente, ha entendido que el problema era de participación. Es necesario que el templo vuelva a poseer dignidad y sacralidad. Y ha señalado los dos momentos fundamentales, la cualidad del templo, no para sí misma, sino para que los fieles puedan participar.

Pero el significado del símbolo es una discusión sin fin, y nos podemos perder en ella. ¿Qué quiere decir símbolo? Todo tiene que ser simbólico, pero simbólico en su contenido: no es necesario dar una forma concreta. El ambón es el punto desde el cual escuchamos la palabra de Dios. ¿Será un lugar importante? El ambón es el sitio desde el cual Dios nos habla. Pero no tenemos por qué hacer un bloque de mármol con boca y dientes para que se entienda que desde ahí sale la Palabra de Dios. ¿Cómo podemos dar un valor simbólico al ambón? No lo podemos hacer poniendo ángeles con alas, como me parece que se ha hecho en la catedral, creo, de Vicenza. El problema existe, pero lo difícil es intentar ofrecer una significación a través de fórmulas o bien literarias o bien inventadas.

Me permito hacer una observación sobre tu iglesia [dirigiéndose a Steven Schloeder]. Tu realización de doce pilares es algo estupendo, porque doce simbólicamente es un valor perfecto, porque es un número importante. Doce. Pero luego, yo no diría que es doce como los apóstoles: no me interesa esto. O bien, por ejemplo, que las ventanas son veinticuatro como los ancianos del Apocalipsis. Perdona, no es ésa la cosa importante, como cuando se hace una iglesia con tres puertas porque representan a la Trinidad. La Porciúncula de san Francisco tiene una sola puerta y funciona perfectamente. Quiero decir con esto que la simbología, el problema del símbolo, es algo tan importante que tiene que emanar de situaciones mágicas del conjunto, de una carga cultural de la obra que al final se vuelve verdaderamente simbólica como espacio sagrado. No podemos degradarlo diciendo: «He hecho algo simbólico porque hay tres puertas en la iglesia, hay tres escalones que suben, hay cuatro...» Es decir, no es necesario. Y nosotros no tenemos que creer que poniendo tres puertas en la iglesia obtenemos una calidad mayor, ni decírselo a los demás, porque no es necesario. La cualidad simbólica es algo demasiado difícil como para cortarlo en lonchas y distribuirlo de esta manera.

Está claro que cuando usted habla de la tradición de la Iglesia a lo largo de los siglos — de lo que los arquitectos, construyendo las iglesias del pasado, han podido transmitirnos a propósito de potencialidad espiritual-, está hablando de algo excepcional. La iglesia gótica, por ejemplo: ¡claro que nos quedamos extraordinariamente asombrados! Porque es algo que no conseguimos ni imaginar. Una potencia de este tipo, que proporciona en todos sus detalles la sensación de algo que va más allá de lo humano, de algo que se acerca al misterio... Yo no utilizo mucho el adjetivo «divino», pero, quiero decir que toda esta potencialidad, escuchen señores, debería estar dentro de nosotros como patrimonio genético adquirido en nuestro ADN. Hasta el punto de que cualquier cosa que pongamos en la hoja de papel ya debería contener algo de la calidad que nos llega de los griegos por su excelencia, de los romanos por su potencia expresiva, de todas las iglesias que han sido construidas por el sentido de la perfección mágica; e incluso, desde la ciudad convulsa, desordenada, algunas veces potente.

Siempre que entro en una iglesia antigua tengo una sensación espacial de paz. El espacio, de repente, se convierte en tranquilo, emblemático, sublime, simbólico, porque esa arquitectura estaba hecha de una forma mágica. Pero esta sensación de lo simbólico que recibo las iglesias antiguas, no la recibo porque sepa que las columnas son veinticuatro más tres como eran los apóstoles cuando se juntaron con tres amigos que encontraron por la calle. La recibo, digamos, por la potencia expresiva que nosotros tendríamos que llegar a traducir y a condensar también en las cosas modernas que hacemos hoy en día. Claro, nosotros nos movemos en un espacio que empieza desde una nueva sencillez; miramos a la liturgia como indicación de contenidos que nosotros tendríamos, antes que nada, que descubrir, y luego intentar secundar, ponernos a su servicio. Y esta atención, este darse cuenta de la potencia y de los contenidos de la liturgia, está claro que puede ser alcanza- 
da con la ayuda de las nuevas normas que la liturgia ha dado para poner en evidencia unos determinados fenómenos. Por ejemplo el de la participación, que no es una participación física y ni siquiera auditiva, sino una participación que parte de la convicción directa que debería derivar de una cultura de información antes de llegar a la iglesia.

Pero cuando tenemos que poner todo esto sobre la mesa, deberíamos tenerlo ya dentro de nosotros, habiendo absorbido todo por tradición. Y no es nunca una tradición que se plasma: cogemos una forma y la colocamos aquí. No. Cogemos, en cambio, la cualidad espiritual de la forma que colocamos aquí, cogemos la potencia, la energía de esa iglesia, y la ponemos aquí. Cogemos, digamos, el sentido de algo mágico, infinito, de esa iglesia y lo traemos a la nuestra. Pero ignorando la forma. Es imprescindible ignorar la forma de los demás, es inútil que llevemos con nosotros el fuste o la base de la columna jónica. Los griegos decidieron que la columna tenía que apoyarse en la base jónica. Esta decisión, tradicionalmente, tuvo tanta potencia que se ha enraizado en todo el género humano, de todo el globo, de arriba abajo, de modo que nadie en el mundo, por los siglos de los siglos, puede hacer una columna si no pone por debajo de ella la base de la columna jónica. Porque esta fuerza expresiva de la forma tuvo el enorme poder de connaturarse con el ADN humano, de tal manera que el ojo del hombre no puede ya prescindir de ella. Pero nosotros no tenemos por qué hacer una base jónica en cada pilar que hagamos. Deberíamos tener dentro de nosotros la potencia expresiva de ese objeto para poder decir: «¿Sabes qué? La próxima vez que haga un techo, lo haré con la misma potencia expresiva de la columna jónica.» Esto es lo que yo llamo tradición: cojo la columna jónica y la transformo en algo que se encuentra en el techo pero que no tiene nada que ver con esa forma.

Perdón por la confusión. Pero es necesario que esta confusión la tengan que soportar ustedes también. ¿Por qué la tengo que sostener sólo yo? No me parece justo.

\section{JESÚS LEACHE}

Bueno, si antes era difícil intervenir, ahora se ha puesto todavía más complicado. Porque yo creo que en estas situaciones todos pensamos lo mismo: que ahora necesitaríamos cinco minutos de silencio absoluto para poder ordenar y decantar todo esto que hemos ido oyen- do, sobre todo lo que has contado tu Glauco, que me ha parecido sencillamente magistral. No pensaba decir nada, pero es que tengo que decirlo, porque el campo de las ideas y el campo de la crítica, el campo de la misión arquitectónica está tan empobrecido en nuestros días que resulta absolutamente refrescante oírte hablar con esa claridad de confusiones, con esa sinceridad, con esa vitalidad, como tu dices, que resulta envidiable y un ejemplo para todos nosotros.

Dos cosas diré nada más, porque realmente no se me ocurre nada que aportar a todo esto. A la pregunta que hacía Giorgio, está claro que después de lo que hemos oído la respuesta es no. La respuesta es no, que es bastante, ¿no?

Me congratula ver que el fondo de la cuestión - por lo menos en lo que a nuestras intuiciones se refiere, quizá con menos erudición, quizá sin quizá- es el mismo que el que aquí se está planteando. O sea, que cuando uno va al resumen de la cuestión, pues se encuentra siempre lo mismo. Y eso es también un descubrimiento en esta tarde de hoy, porque no es habitual encontrar un nivel de discusión sobre este asunto con este tono.

$\mathrm{Y}$ con respecto de la tradición, recuerdo una frase de Louis Kahn que puede llegar a resumir todo el problema. No sé si lo recordaré bien, pero dice algo así: «Lo que ha sido, ya fue; lo que es, ya ha sido; y lo que será, ya es». Y hablando de esta cuestión que nos ocupa aquí, yo añadiría que en la arquitectura religiosa «lo que no funciona, no ha sido».

Estoy perfectamente de acuerdo con Iago en ese ir de la mano de la tradición. No, la tradición no es algo rancio o casposo que alguien se ha tenido que quitar de encima, sino todo lo contrario: una tradición es algo sobre lo que ineludiblemente está fundamentado nuestro ADN. Podríamos resumir todo ello diciendo que nada podemos inventar saliéndonos del carril de la tradición.

\section{FERNANDO TABUENCA}

Bueno, tampoco puedo decir mucho más, pero sí querría dar una opinión concreta. Efectivamente, yo pienso que quizá desde el Concilio Vaticano II se ha abandonado una cierta tradición de cómo se construían arquitectónicamente las iglesias. Y creo que se ha insistido excesivamente en esas ideas que tienen que ver con la asamblea, con la participación de los fieles, etc. Y se 
ha incidido en aspectos que, por así decirlo - y soy consciente de que esquematizo bastante - son casi funcionales: se ha asimilado el espacio sagrado a un espacio civil, casi a un auditorio.

Vemos muchas iglesias de los últimos cuarenta años, en las que, efectivamente, con el concurso de toda esta serie de técnicos que nos asisten a los arquitectos - especialistas en acústica, en iluminación, etc.- se ha pretendido que el espacio funcionara. Quizá somos herederos de Le Corbusier, y eso también ha incidido en estas nuevas cuestiones que se han planteado a partir del Concilio Vaticano II. De manera que la «máquina de habitar», que para Le Corbusier era la vivienda, en el caso de la iglesia se traducido en cierta forma como la «máquina de rezar». Por eso, pienso que la asunción de esos principios más funcionalistas, asamblearios, al mismo tiempo llevaban aparejada una cierta pérdida de trascendencia de lo que ha sido durante siglos ese espacio místico. Y creo que es una gran pérdida.

Desde que la iglesia cristiana adoptó la forma de la basílica romana - una forma no prevista o no diseñada para la congregación cristiana-, esa forma ha funcionado durante siglos, tal vez porque tenía una proporción, una altura o una forma de entrar la luz determinada, y eso hacía que el pueblo ahí reunido se viera ayudado por la arquitectura a esa conexión con lo trascendente. A pesar de sus inconvenientes funcionales - yo creo que todos hemos asistido a misa detrás de una columna de una de las capillas laterales, no viendo absolutamente nada de lo que ocurría en el altar- sin embargo esa forma - curiosamente tan antifuncionalha pervivido durante siglos. ¿Por qué? Pues porque tenía otros valores trascendentes - $-\mathrm{y}$ aquí es donde yo quiero incidir - que son mucho más importantes que la mera funcionalidad.

Estoy diciendo de otra manera algo que ya se ha dicho aquí, pero bueno, insisto sobre ello. Creo que tenemos que hacer el esfuerzo - aún con cierta pérdida de funcionalidad o de lo que puede entenderse como la participación de la asamblea en el misterio de la celebración de la misa- de construir espacios que nos ayuden más a conectarnos con ese aspecto tan intangible y tan difícil: situarnos en una situación emocional que nos facilite realizar lo que de verdad es la función de una iglesia, por encima de los aspectos más pedestres de la visibilidad, de la acústica, de la iluminación. Yo creo que, en el fondo, con esto hablo de algo que creo que es más funcionalista que el mal entendido funcionalismo. Porque la función de una iglesia precisamente debe ser esta: ayudar a los fieles a sentirse hermanos de una comunidad, pero al mismo tiempo, conectados con algo trascendente, con la divinidad.

$\mathrm{Y}$ acabo recordando, en ese sentido, una anécdota que nos contaba siempre un profesor de proyectos que tuvimos en Pamplona, Javier Carvajal, que fue un gran maestro para todos nosotros. La anécdota que contaba -no se si real o inventada: yo me la creo, aunque en el fondo me da igual - trataba de un japonés — por lo tanto, un no católico - que llegaba a París como turista. Llegó a Notre-Dame, se enfrentó a su fachada y se quedó sobrecogido por la proporción, por el arte. Traspasó el umbral de Notre-Dame. En aquel momento, la luz entraba por las vidrieras y creaba unos reflejos de colores en los pilares, en la piedra, una luz maravillosa; y al mismo tiempo estaba sonando el órgano, una cantata de Bach. Este hombre, que era un hombre sensible, se quedó tan emocionado que en aquel mismo momento dijo: «Algo tan bello sólo puede haber sido hecho por Dios; sin duda, ésta tiene que ser la religión verdadera.»

Es lo que con palabras mucho más torpes he intentado decir yo: que como arquitectos no debemos olvidar que nuestro objetivo, nuestra misión cuando intentamos proyectar una iglesia, es que tenemos que estar a la altura de la creación de ese espacio místico, llamémosle como queramos. Es una labor muy difícil y al mismo tiempo muy bonita, y que nos hace sentirnos responsables por considerarnos un eslabón más dentro de una larga tradición, que en el fondo, es la historia de la arquitectura occidental.

\section{JAVIER VIVER GÓMEZ}

Mi intervención tiene que ver con lo que ha dicho Steven. Yo creo que la cuestión no es que nadie se plantee, de hecho, la actualidad o la validez de los símbolos de la propia liturgia. Eso es algo que hemos recibido y que forma parte de una tradición, que es una tradición viva, en la que símbolos e imágenes —en la Escritura tenemos miles - van apareciendo o desapareciendo en relación con los distintos momentos temporales. Ese fluir forma parte de esa tradición viva. Me parece que la cuestión no es discutir sobre esos símbolos ni sobre la liturgia, aunque también es cierto que la liturgia es la 
misma siempre, pero aparecen aspectos nuevos que se ponen de manifiesto. Un ejemplo es el concepto de Pueblo de Dios: siempre estuvo ahí, pero en el Concilio Vaticano II surgió como una novedad.

Y sin embargo, a mí me parece que la clave estaría en ver cómo se tratan, cómo se plasman en las formas esos símbolos y esa misma liturgia. Un ejemplo podía ser el tema de la luz. Es un símbolo clásico, pero sin embargo nos obliga a replantearnos algunas cosas. En una sociedad como la actual, en la que en muchas partes del mundo el contacto que tienes con la luz es una pantalla de plasma, cabe preguntarse si no tendríamos que responder de otra manera a esa percepción global de los símbolos de siempre, y si no hay que decir algunas cosas de forma distinta.

También lanzo otra pregunta, que quizá no pueda ser contestada ahora, pero sí tal vez en sesiones sucesivas. Es sobre la inculturación de la fe. Me parece que la respuesta de un arquitecto, de un escultor o de un músico, no ha de estar dirigida exclusivamente a una determinada comunidad local, sino que tiene una responsabilidad global de cara a esa inculturación de la fe. O sea, que la propia fe debe dar respuesta a las demandas que se constituyen social y culturalmente sobre una cuestión candente. Y eso siempre lo ha hecho la Iglesia a través del arte sacro. El arte sacro ha ido transformando la cultura — la propia sociedad-, aunque no fuera explícitamente religiosa.

\section{MERCEDES PÉREZ DEL PRADO}

Yo soy arquitecto, profesora de la Universidad de Sevilla, y he tenido la fortuna de hacer una iglesia. Para mí hay una cosa que es fundamental. Vamos a ver: el Concilio Vaticano II hace algo muy importante, que es volver a subrayar la idea de que Dios es cercano: es misterioso pero es cercano. Pero la arquitectura contemporánea se ha quedado sólo con la idea de que esa cercanía era de la comunidad (que, en efecto, es esencial, es uno de los temas del Concilio Vaticano II). Y muchas veces se ha perdido esa dimensión del misterio, de ese Dios que es también misterio.

La arquitectura no puede obviar estas dos cosas, tiene que combinarlas. Tenemos que proyectar espacios para el encuentro con un Dios que es cercanía y misterio al mismo tiempo. La arquitectura más tradicional ha subrayado la idea de Dios-misterio. Podemos aprender mucho de ella, por ejemplo, de cómo se utiliza la luz.
Pero todas esas intervenciones que se han hecho en la historia de la arquitectura contemporánea, dibujando precisamente ese espacio que crea cercanía, tampoco se pueden obviar. No podemos agarrarnos a la tradición porque ahora mismo nos sintamos impotentes. Tenemos que seguir explorando y buscando. 